\title{
Graceful Interactions and Social Support as Motivational Design Strategies to Encourage Women in Exercising
}

\author{
Daphne Menheere ${ }^{\dagger}$ \\ Industrial Design, TU \\ Eindhoven, the Netherlands
}

\author{
Carine Lallemand \\ Industrial Design, TU \\ Eindhoven, the Netherlands; \\ University of Luxembourg Esch- \\ sur-Alzette, Luxembourg
}

\author{
Bram Monkel \\ Industrial Design, TU \\ Eindhoven, the Netherlands
}

\author{
Ilse Faber \\ Industrial Design, TU \\ Eindhoven, the Netherlands
}

Steven Vos

Industrial Design, TU Eindhoven, the Netherlands; School of Sport Studies, Fontys University of Applied Sciences, Eindhoven, the Netherlands

\author{
Eindhoven, the Netherlands
}

Industrial Design, TU

\begin{abstract}
KEYWORDS
Constructive design research, graceful interaction, wearable technology, social support, aesthetics of interaction

ACM Reference format:

Daphne Menheere, Carine Lallemand, Ilse Faber, Jesse Pepping, Bram Monkel, Stella Xu and Steven Vos. 2019. Graceful Interactions and Social Support as Motivational Design Strategies to Encourage Women in Exercising. In Proceedings of Halfway to the Future (HTTF 2019), November 19-20, 2019, Nottingham, United Kingdom. ACM, New York, NY, USA, 10 pages. https://doi.org/10.1145/3363384.3363404
\end{abstract}

\section{Introduction}

Physical inactivity is a growing public health concern, leading to increased awareness of the importance of an active and healthy lifestyle [37]. More and more people are thus having positive intentions of being physically active [28]. Even though sport was once an activity practiced mainly by men, one witness positive developments in gender equality in this area with considerable growth of women participating in sport [32].

The main challenge for many people is to translate their positive intentions into actual, preferably long-term, exercise behavior [28]. Most studies indicate the drop-out rate for exercise interventions is around 50\% [3, 17], where women are more likely to discontinue exercising as compared to men. This is due to more unforeseen perceived barriers but also because of the greater importance women attach to social support [17].

In line with the growing awareness of the importance of physical activity, there has been an exponential increase in the use of sport-related wearables. Indeed, the 
global market size of smart wearables fitness and sports devices, supporting exercising and motivating people and allow them to monitor their progress [19], is expected to keep growing [34]. However, the question arises whether these devices only reach a small target group that already has a strong affinity and identify with sports and exercise and thus is more interested in capturing health and sportsrelated data $[11,40]$. Other parts of the population, who perceive sports as a short-term cost (e.g., costs energy, time, sweating, pain) [7] and value social support, might be less addressed. Studies show that this type of social thinking seems to appeal to women in particular [17]. Furthermore, research also indicates women mention feeling uncomfortable wearing activity trackers [33] due to the sporty and bulky appearance of the devices, preferring ones that are more graceful [22, 24].

In this paper, we introduce the design of Grace, a piece of jewelry that allows women to share their exercise intentions with friends to enable social support. While the current design space of wearable sports devices mainly focuses on quantification, we extend it here by relying on a qualitative aesthetics of interaction $[9,21]$. Away from the use of numbers as a feedback mechanism, our approach combines meaningful gestures with a specific aesthetics of the artifact. Through an expert study involving industrial designers, we contribute to the field by defining the interaction attributes of graceful interaction in product design. We then designed Grace to embed the notion of graceful interaction. Grace acts as a propositional object enabling us to investigate how to design for exercise motivation through social support and graceful interactions.

\section{Related Work}

Along with the increased popularity of sports, there has been an exponential increase in the development of sportrelated wearable technology [34]. These devices enable body-monitoring and data tracking, offering the possibility of improving personal health outcomes. Even though there is a general acceptance that people are different, most of these devices still tend to take a "onesize-fits-all" approach of stimulating exercise performance or competition [26]. These quantitatively driven approaches might not suit "all" since many people prefer thinking in stories (i.e., qualitatively) [26] rather than in numbers (i.e., quantitatively). Additionally, the one-sizefits-all approach also influences the perceived aesthetics of the devices, where women have indicated to feel uncomfortable wearing these in previous studies [11].

\subsection{Quantification in Body-Monitoring}

The current paradigm of sports tracking is that everything can and is being quantified (e.g., by the use of numbers and graphs). The idea here is to create better cognitive awareness among users about their state of health or performance to eventually change their lives for the better $[10,19,33]$. Even though this paradigm speaks to a particular type of encouragement, a lot of people are not encouraged by knowing that they are faster or stronger than others (or than they used to be), but they are encouraged by being part of a community [17,39]. The use of such a paradigm of exercise encouragement through a more qualitative social interaction seems to be a relatively unexplored area [21]. Yet it seems promising to give social meaning to sport-related feedback [23] through a more abstract and poetic way [38] by incorporating ambiguity and visualizing uncertainty in the feedback [10]. In the present paper, we therefore argue for the use of a more qualitative aesthetics among sport-related wearables.

\subsection{Public Performance vs. Social Support}

The nature of the exercise environment and sport-related technology are of masculine origin [4], with performance and competition often being the main stimuli for motivation [18, 19]. Even though these motivational triggers drive a segment of female exercisers, research shows that for certain groups of women, health and social support are more effective motivators to exercise [39]. Social support as a motivational strategy can increase adherence in exercise [31]. Numerous studies thus advocate for including social features in sport-related technology [30,35]. This can be done, for instance, by integrating social elements in training sessions of athletes to make sports more fun. One example is "Jogging over a Distance" by Mueller et al. [25], where individual runners can run together in different physical locations via audio. A different approach was taken in RUFUS [43], a system developed to allow people to cheer from a distance for participants in running competitions. Even though these designs facilitate social experiences for individuals throughout the exercise, lack of social support is primarily experienced before the exercise itself and is proven to affect motivation negatively [27], indicating the importance of integrating social support before the actual training. External online fitness platforms (e.g., Runkeeper (C), Strava (C) try to bridge that gap by enabling people to share their sports performance with others [36]. Even though these platforms allow for social support throughout the day, it is performance and competition- 
Graceful Interactions and Social Support as Motivational Design Strategies to Encourage Women in Exercising

driven and whether this is desirable for everyone is questionable [41].

\subsection{Appearance of Sport-Related Wearables}

Previous research revealed that some customer segments, especially women, can feel uncomfortable wearing sportrelated wearables [15]. This is partly due to the sportive and masculine appearance of the devices. In a study where different activity trackers were rated by user impressions among women, the ones that hinted towards pieces of jewelry and a graceful aesthetics were preferred over the sportive and masculine looking ones [22, 24], indicating the importance of also striving for a less sportive look and feel within these types of everyday objects. The current market only presents scarce examples of sport-related wearables (e.g., BellaBeat (c), Selah Cuff (c), Tory Burch Fitbit (C) considered pieces of jewelry.

Another reason why women felt uncomfortable wearing these devices was due to the perceived identity (and the social acceptability) associated with them, having a negative impact on the person wearing it [11]. One might prefer a more personal approach of interaction opposed to the currently open and publicly visible feedback [23] since not everyone is interested in or feel comfortable with showing that they are wearing a sportrelated device [33]. This is why we argue, when designing this type of device, to shift its look and feel from a sportrelated wearable to interactive jewelry.

\subsection{Interactive Jewelry}

Jewelry has a long history of being an explicit private and social communication tool [42] while still closely intertwining in our everyday lives like no other wearable does [2]. The emergence of wearable technologies has expanded the opportunities for jewelry to be a 'communication tool' by integrating a digital layer to the tangible object [38]. Interactive jewelry thus can dynamically react on wearers inputs following different interaction modalities (e.g., usually touching modalities such as fidgeting, hovering, sliding or, rotation elements) $[2,38]$. Since these types of interactions can still integrate the poetic qualities of jewelry, like sensorial engagement and intimacy (toward other people, places and self) [2], we highlight the potential of interactive jewelry to integrate social support for exercise engagement among women, when aiming for qualitative interactions.

In this paper, we focus on graceful interaction and social support as motivational design strategies. In the following section, we describe the iterative design process
HTTF 2019, November 19-20, 2019, Nottingham, United Kingdom

of Grace as a reflection on the aforementioned discussed perspectives.

\section{Designing Graceful Interactions}

While easily linked to a certain form of beauty, attained through posture and motion, it is hard to fully grasp what constitutes gracefulness [6]. Common examples associated with gracefulness are swans or ballerinas (hence the figure of speech 'graceful as a swan'). Transposing this concept to the act of design, thus represents a challenging endeavor, with very few attempts in the HCI literature so far [15]. How would the aesthetic quality of gracefulness materialize in interaction design?

\subsection{Materializing Gracefulness in Interaction Design: An Exploratory Study}

To explore how the concept of graceful interactions could materialize in a design artifact, we invited industrial designers $(\mathrm{N}=22)$ to participate in a short study. Using the Interaction Vocabulary Cards by Diefenbach, Lenz \& Hassenzahl [9], we asked them to describe how a graceful interaction with a physical product would feel/look like. Participants were provided with the following definition of gracefulness (combining definitions by [6] and [8]: "Gracefulness is characterized by elegance or beauty of form, manner, movement, or speech. It is elegant. Grace is the appearance of an easy presence (graceful movements appear as easy and effortless). And such presence involves a harmonious relatedness to one's context." [6].

The Interaction Vocabulary consists of 11 seven-point semantic differential items to describe the interaction. The participants were asked to evaluate only the pairs of words that they consider relevant to design for graceful interactions and to leave the others blank. They were also instructed to leave aside aspects that they consider relevant yet dependent on the type of product or use context. After the assessment of the 11 items, we asked the participants to select 3 attributes, out of the aforementioned items, which they consider the most important interaction attributes to design for gracefulness. Out of the 22 designers, 18 answered that open-ended question (one participant only provided two attributes, and another gave an attribute that was not part of the initial list, namely 'harmonious').

Our results show that seven attributes are associated with gracefulness in the context of interaction design: slow, fluent, uniform, constant, precise, gentle, and targeted (Figure 1). Amongst those, fluency (14), gentleness (12) and slowness (7) were selected as the most important attributes for a graceful aesthetic of interaction. 


\begin{tabular}{|c|c|c|c|c|c|}
\hline Attribute 1 & $\begin{array}{l}\text { Frequency } \\
\text { Attribute } 1\end{array}$ & $\begin{array}{c}\text { No } \\
\text { Response }\end{array}$ & $\begin{array}{l}\text { Frequency } \\
\text { Attribute } 2\end{array}$ & Attribute 2 & \\
\hline Slow & 15 & 6 & 1 & Fast & \multirow{3}{*}{$\begin{array}{l}\text { Seven attributes of } \\
\text { graceful interaction } \\
\text { for product design }\end{array}$} \\
\hline Stepwise & 2 & 1 & 19 & Fluent & \\
\hline Instant & 4 & 15 & 3 & Delayed & \\
\hline Uniform & 14 & 6 & 2 & Diverging & \multirow{4}{*}{$\begin{array}{l}\text { Fluent } \\
\text { Gentle } \\
\text { Slow }\end{array}$} \\
\hline Constant & 15 & 7 & 0 & Inconstant & \\
\hline Mediated & 7 & 8 & 7 & Direct & \\
\hline Spatial Separation & 1 & 13 & 8 & Spatial Proximity & \\
\hline Approximate & 2 & 3 & 17 & Precise & \multirow{4}{*}{$\begin{array}{l}\text { Precise } \\
\text { Constant } \\
\text { Uniform } \\
\text { Targeted }\end{array}$} \\
\hline Gentle & 16 & 6 & 0 & Powerful & \\
\hline Incidental & 1 & 7 & 14 & Targeted & \\
\hline Apparant & 4 & 12 & 6 & Covered & \\
\hline
\end{tabular}

Figure 1: Attributes used by design professionals $(\mathrm{N}=22)$ to describe a graceful interaction, using the Interaction Vocabulary [9].

To incorporate the most important elements for graceful interaction elicited through the survey (slow, fluent, and gentle), we conducted an iterative and explorative design process with close user involvement. In this design process, the goal was to enable social support among women who want to exercise by use of a qualitative approach.

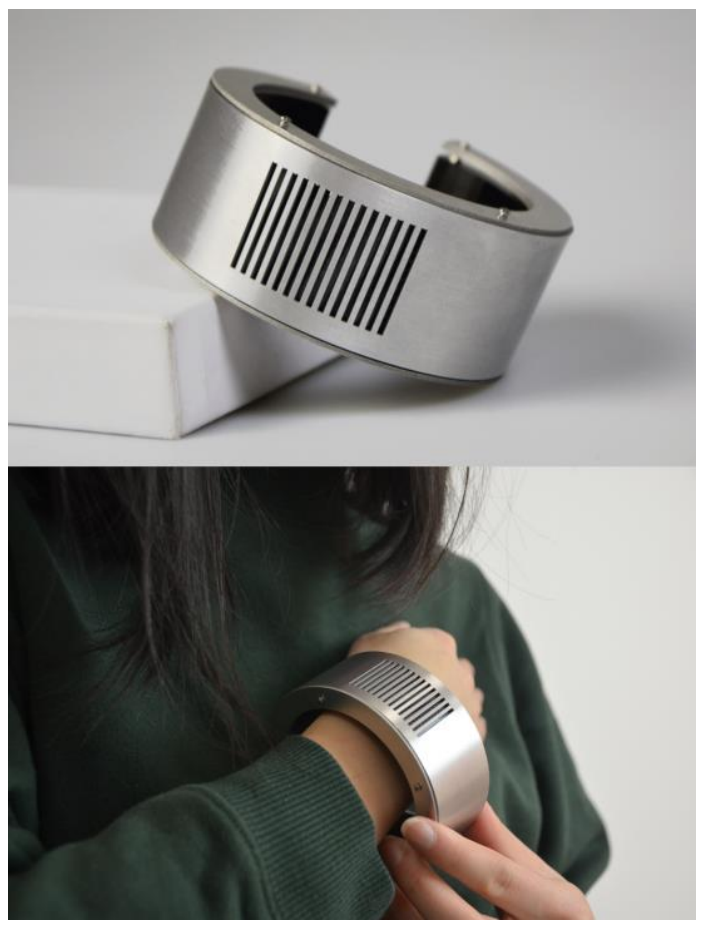

Figure 2: Grace, a piece of interactive jewelry, enabling women to share their exercise intentions

\section{Design of Grace}

Grace is a piece of jewelry (Figure 2) that encourages women to share and support exercise intentions with friends through graceful interactions. Through Grace, users are able to see whether friends have the intention to go exercise that day, and eventually if they actually went. The same information is also shared about themselves.

This commitment-based way of motivating is closely intertwined with an increased feeling of group coherence and social support. To amplify the awareness of sharing goals and accomplishing them together, Grace also enables to cheer for your friends, stimulating them to get active, or celebrating with them for turning their intentions into action. Relying on a qualitative aesthetics of interaction, Grace embeds the notion of gracefulness as a novel perspective, as opposed to the current quantification trend.

Grace entails several touch, motion, and mid-air gesture interactions: (1) To plan an exercise, the hand is placed on the heart as to mimic the salutation of promise. The display, divided into slots for different friends, will now display skewed stripes. (2) When the user is done exercising, she taps herself three times on the chest, showing off a feeling of pride, and changing the stripes into mellow post-workout waves. (3) Lastly, to cheer (regardless of their effort) for friends with a lively zig-zag pattern, you hold your hand on your heart for a feeling of connectedness (Figure 3). By supporting the user values within Grace, we focus on implementing the symbolic meaning of committing to exercising [1]. 

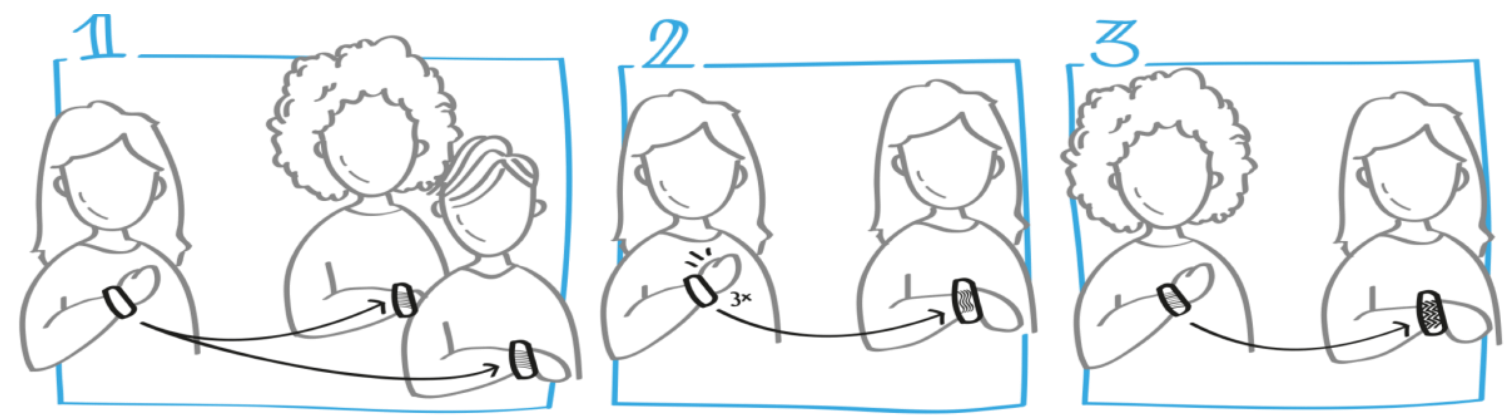

Figure 3: Grace interactions for committing to exercising (1), sharing one's achievement (2) and cheering for friends (3)

\subsection{Underlying Design Principles}

Aesthetics of Interaction. We used the Interaction Vocabulary [9] to describe the interaction qualities of Grace. It consists of eleven descriptive, non-judgmental, non-technology bound attributes of interactions. The interactions with the bracelet are intended to be subtle and graceful, to propose a different motivational strategy opposed to the performance and competition-driven approaches. Translating these notions into the vocabulary of interaction led us to design Grace's interaction style as slow, gentle, fluent, and covered. The first three elements were considered the most important for graceful interaction in our exploratory study. While described by expert designers as a context-dependent dimension (i.e., depending on the context, an interaction can be graceful while being either 'apparent' or 'covered'), we choose to add the attribute "covered" to represent a feeling of intimacy, which was deemed important in our context.

Slow and gentle interaction qualities allow us to distinguish Grace from activity-related devices focused on performance, which are usually designed as being fast, powerful, and precise and use numbers to provide users with feedback. Slowness is expressed in the design of Grace in the way the feedback is received throughout the day and cannot be seen on demand. We translated Gentleness in all the styles of interaction within Grace, placing your hand on the heart to make a commitment and the gentle turning of the bracelet to see the moiré effect.

The choice of a fluent interaction style is linked to gracefulness, corresponding to the definition of graceful movements as "apparently easy or effortless" [6]. Fluency is translated within the design of Grace in the gestural interaction, as well as the smooth act of fidgeting, making the feedback more visible.
Users are able to personalize their visuals (i.e., the moiré effect) and therefore construct individual meaning to the patterns that are linked to different types of feedback. In this way, this personal information remains covered, meaningless to other people, in the immediate vicinity of the user, who is not familiar with the constructed patterns. The aim was to integrate a subtle and personal interface while still being valuable to the wearer. Furthermore, when the moiré effect appears (Figure 4), this enhances the overall appearance of Grace.

Moiré Patterns as Ambiguous Information Representation. To provide feedback in a poetic and abstract form (as opposed to the quantified data provided by most activity trackers), we made use of the moiré effect (Figure 4). This is a visual phenomenon that occurs when two similar types of patterns are moved over each other, thus creating a new pattern. When fidgeting with Grace,

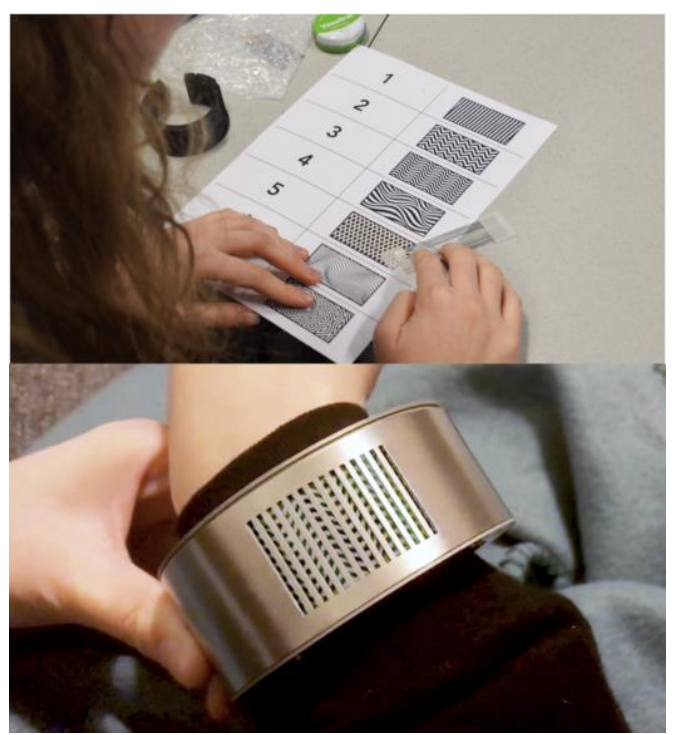

Figure 4: Testing different moiré patterns and final implementation of a moiré pattern in Grace 

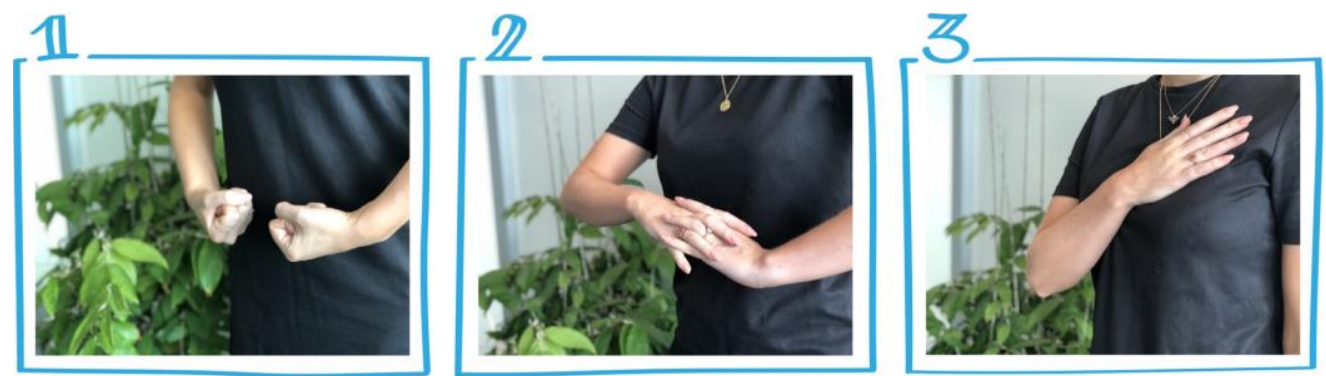

Figure 5: Experiencing multiple poses through role playing: power poses (1), fun or wacky poses (2), symbolic poses (3)

the top layer of the bracelet is moved over the bottom layer (supporting a covered aesthetics of interaction again), creating this Moire effect. The top layer is part of the bracelet and keeps its shape, while the bottom layer is an integrated e-paper display, enabling the possibility to change the pattern.

Commitment to Exercise. Users need to interact with the device to indicate their exercise planning and activity. Cognitive interactions tend to disrupt the user's day-today routine, so the goal was to choose a relevant, motionbased gesture that can be performed without an active focus on the interaction itself. Multiple poses were experienced through role-playing among the designers (Figure 5). Power poses were considered for their empowering, encouraging effect, but were dropped because they could not be performed subtly (1). Fun or wacky poses were discarded for the same reason (2). Ultimately, a pose associated with a promise to the heart was chosen, representing the promise to exercise made to oneself (3).

Social Support and Feeling of Togetherness. The aim of Grace is to exercise individually while experiencing a feeling of togetherness with friends, proven to have a motivating effect [20]. According to Hassenzahl et al. [16], this feeling of relatedness, mediated through technology, can be achieved through awareness, physicalness, and joint-action, amongst other strategies.

The awareness strategy consists of "sharing different types of ambient information about current activities or moods among partners, without a conversation or doing anything together" [16]. Reciprocal self-disclosure and ambiguity [12] are both described as essential principles to design for awareness. With Grace, awareness is achieved through the received updates throughout the day presented in an ambiguous way through the moiré effect, where the user understands the information and raises awareness while its meaning remains unknown to others.
The physicalness strategy includes artifacts that "mediate a feeling of physical intimacy, simulating secondary effects of the physical proximity of meaningful gestures" [16]. Grace embeds physicalness in the way the user intuitively interacts with Grace through fidgeting. Through this intimate interaction, the moiré effect will appear contributing to the look and feel of the bracelet. Lastly, artifacts allowing for carrying out an action together fall into the joint action strategy [16]. Jointaction comes forward within the Grace concept in the sharing and celebrating of goals, as well as in the behavioral interdependence between women.

\subsection{Technology and Realization}

To measure the different expressions the user makes: (i) committing to exercise, (ii) finishing the exercise and (iii) supporting for a friend, the microcontroller calculates the movement and measures the angle of the wrist through the accelerometer and gyroscope (Figure 6). Based on these values, the microcontroller identifies which gesture is performed and thus adjust the e-paper display (Wemos 2.13-inch E-Ink) accordingly, visualizing various moiré patterns linked to the different expressions.

Fitting the electronics, while remaining its accessibility as well as combining the plastic base with a rotating aluminum body was a major challenge in the design. Following the validation of the motivating power of the concept, a more robust and eminent prototype was desirable to be able to validate the interactions and visualizations. The choice was made to use metals with a silver hue such as stainless steel or aluminum, due to women's preferences of the aesthetics of activity trackers being luxurious, graceful, and feminine [24].

To create the moiré effect, it was decided to make use of an outer rotatable ring. From here, multiple different prototypes and material explorations were created (Figure 7), validating the effectiveness of the moiré effect, and identifying the location of electronics and wire outputs. 
During the validation, it was seen that the full circle design was not associated with gracefulness, mainly due to its corresponding size. To preserve these values, a cuff with the ability to slip over the wrist with ease, ensuring a smaller size and a more feminine look was chosen as the salvation. The size for this cuff was tested (Figure 7), concluding a size of $65 \mathrm{~mm}$ inner diameter, corresponding with a "large" for different cuffs at local jewelry stores.

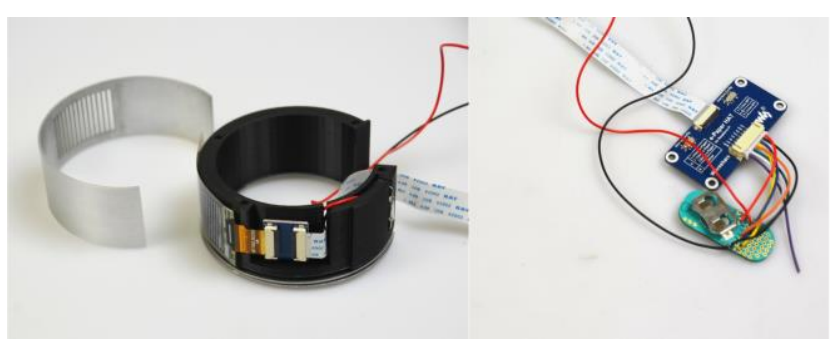

Figure 6: Electronics of Grace: left, integrated e-paper display. Right, Light Blue Bean with accelerometer

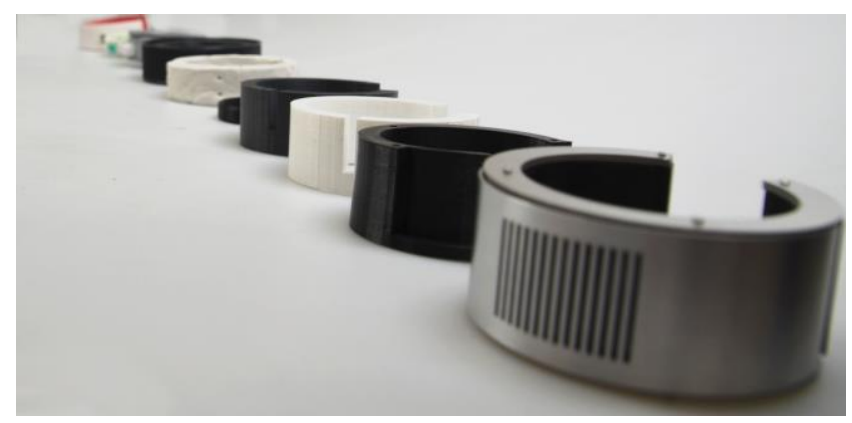

Figure 7: Material exploration of Grace cuff

\section{User Study}

To gain first insights into how our target women experience Grace, we set up an exploratory user study. We investigated whether the different interactions with Grace and the feedback given by this interactive piece of jewelry were considered as graceful. We also assess the perceived meaningfulness of qualitative social support mechanisms as a motivational strategy.

Three participants wore and interacted with Grace for one day on which they had the intention to exercise. The women participating in the study all sometimes indicated to experience difficulties in turning their exercise intentions into actual exercising that day. Since we only had one working prototype, we used a Wizard of $\mathrm{Oz}$ approach to simulate the intentions and support of two other friends. After wearing Grace for a day, the women were interviewed about their experience, how they interacted with the bracelet, and how they felt wearing
Grace throughout the day. The interviews were transcribed, analyzed via thematic analysis, and translated from Dutch to English by the researchers.

Cheering component of Grace. All three participants indicated to value the cheering component of Grace, enabling social cohesion and support. "The function I appreciated most was being able to cheer for others." - P3

Interestingly, they did not only value this for their own motivation (by receiving a cheer from their friends but also themselves) but also being enabled to cheer for others. "I really liked the cheer function; it really had a positive effect when other people were cheering for me. But I've been cheering for myself all day as well." - P2

Subtle yet graceful feedback. The participants indicated to consider the feedback being subtle yet graceful. The notifications were provided in real-time and could not be seen on demand. Therefore, users might miss supporting cheers of friends or friends expressing intentions. Integrating an interaction that makes it possible to recall previous notifications might solve this. "I had to look at it quite often to see whether it changed, approximately four times per hour I think" - P1

"Maybe it was too subtle to notice whether there were changes" - P3

Adding such a feature, will not influence the form of the feedback of Grace, which is important since the unobtrusiveness and feedback subtlety was also considered as an added value by the participants. P3 explicitly mentioned that when they did experience the feedback on demand, it was appreciated that it was not screaming for attention since this was adding to the quality of the aesthetics of the bracelet. "The visualizations were graceful and subtle; it's not a light which is screaming for attention. I really liked that it was abstract and appreciated that the visualization is presented in a more artistic way"-P3

Ambiguity of Visualizations. Some participants indicated they experienced some difficulties recalling the different meanings of the feedback because of its abstract form. However, this was only encountered at the beginning of the day (when they started to use Grace), which improved quickly when interacting with the device throughout the day. "Fidgeting with Grace is nice because you see everything move, but it also adds uncertainty to its meaning." - P1

"The visualizations were abstract, so the different meanings had to be learned; however, they were very easy to learn." - P3

Another suggestion by $\mathrm{P} 2$ was to be able to visualize in real-time when one of your friends is sporting, and to 
express some disappointment perhaps - "and if they are not doing it, to show a sad face." - P2

\section{Discussion and Future Work}

Throughout this paper, we explored the relevance of adopting a qualitative aesthetics of interaction to extend the design space of sports wearables for women. Deliberately positioning this work in opposition to the widespread use of quantification as a motivational strategy [21], we question the current tailoring of motivational design to address the needs of a specific target group and notably amongst women [29]. Our interactive bracelet Grace acts here as a propositional object embedding notions of gracefulness and social support.

Designing for gracefulness is a challenging endeavor, which we addressed in two ways. First, by involving industrial designers $(\mathrm{N}=22)$ in the definition of a graceful aesthetic of interaction. Second, by embedding and materializing these attributes in the design of an interactive wearable in order to gain insights into the effect of a graceful interaction style on exercising motivation.

In addition, through the medium we selected, we uncovered the vast potential space of input interaction enabled by interactive jewelry [2]. The poetic qualities of jewelry, such as sensorial engagement, intimacy and symbolic meaning [42], might appeal to specific target groups and constitute an alternative to the rather sportive and masculine look and feel of current sports wearables $[22,24]$. By not being perceived as activity trackers, jewelry artifacts offer a high potential to personalize the visualization (in our case, through the self-defined Moiré patterns) while also providing an opportunity to cover the interaction (if one does not identify as a sports person).

We combined the qualitative aesthetics perspective with a social support strategy, described in the literature as effective [31], especially for users with less difficult goals who could benefit from social feedback more [14]. Interestingly, we noticed during the design process, how difficult it is to refrain from designing social features promoting competition rather than cooperation. As an example, visualizing in real-time when a friend is sporting to express disappointment could unintentionally promote a certain form of competition or demotivating friction. We decided to focus on the intention and the outcomes (cheering) to stay as close as possible to the supportive social positivity we intended to embrace with Grace.

While conducted on a limited sample and for a short duration, the findings of our user study tend to confirm the relevance of our approach as a complement to existing technology design supporting physical activity.

Of course, while we seem to adopt a rather dichotomous gender perspective on the topic of exercising motivation in the present paper, we acknowledge and do not underestimate the role of other variables in the users' preferences for a specific motivational strategy. Goalfocus, goal-orientation, and other inter-individual differences $[13,14,36]$ definitely play a role in the perception of - and reaction to - different types of motivation. Women can also be motivated by numbers, gamification, or social competition [5], and our approach is not proposed as a one-size-fits-all solution addressing females' needs. Alternatively, the present example aims at opening up new perspectives for designers to provide meaningful, motivational technologies.

In future work, we aim to refine the design of Grace and to conduct a longitudinal field study over several weeks, featuring real interactions between the participants and their friends. From a design perspective, we intend to improve the aesthetics of the bracelet to increase the looks and feel towards a graceful piece of jewelry. At the moment, and mostly due to technical constraints, the bracelet can still be considered as a somewhat 'bulky' prototype, even though its appearance does not reveal its main purpose to encourage exercising. For women to feel comfortable wearing it, it is important to refine the aesthetics of Grace by making use of the full potential of interactive jewelry as a medium for graceful interactions.

With designing Grace, we extend the design space of sport-related wearables for women and inform how to design for exercise motivation through social support and graceful interactions. We believe our work shows a promising and different approach towards a more qualitative way to support women with exercising. The present study thus provides encouraging and inspiring practical implications to designers of wearable technologies. In addition, designers can also use the gracefulness interaction attributes as a starting point for the design of interactive technologies in other application areas.

\section{Acknowledgements}

The authors would like to thank the reviewers for their valuable comments and feedback improving the quality of the paper. We would also like to thank all the participants who contributed to this study. This work is part of the project Nano4Sports which is financed by Interreg Vlaanderen-Nederland. 


\section{REFERENCES}

[1] Michael Allen. 2006. A dual-process model of the influence of human values on consumer choice. Revista Psicologia: Organizações e Trabalho 6, 1: 15-49. https://doi.org/10.1177/136346159303000305

[2] Jatin Arora, Kartik Mathur, Aryan Saini, and Aman Parnami. 2019. Gehna: Exploring the Design Space of Jewelry as an Input Modality. In Proceedings of the 2019 CHI Conference on Human Factors in Computing Systems, 521. https://doi.org/10.1145/3290605.3300751

[3] Janet Buckworth, Rod K Dishman, Patrick J. O'Connor and Phillip D. Tomporowski. (2013). Exercise psychology. Human kinetics, Inc.

[4] Aïna Chalabaev, Philippe Sarrazin, Paul Fontayne, Julie Boiché, and Corentin Clément-guillotin. 2013. The influence of sex stereotypes and gender roles on participation and performance in sport and exercise: Review and future directions. Psychology of Sport \& Exercise 14, 2: 136-144. https://doi.org/10.1016/j.psychsport.2012.10.005

[5] Eun Kyoung Choe, Nicole B. Lee, Bongshin Lee, Wanda Pratt, and Julie A. Kientz. 2014. Understanding quantified-selfers' practices in collecting and exploring personal data. Proceedings of the 32nd annual ACM conference on Human factors in computing systems - CHI '14: 1143-1152. https://doi.org/10.1145/2556288.2557372

[6] Christopher Cordner. 2003. The meaning of graceful movement. Fournal of the $\begin{array}{lllll}\text { Philosophy of } & \text { Sport } & \text { 132-143. }\end{array}$ https://doi.org/10.1080/00948705.2003.9714639

[7] Benedicte I. Deforche, Ilse M. De Bourdeaudhuij, and Ann P. Tanghe. 2006. Attitude toward physical activity in normal-weight, overweight and obese adolescents. Fournal of Adolescent Health 38, 5: 560-568. https://doi.org/10.1016/j.jadohealth.2005.01.015

[8] Dictionary.com Retrieved June 26, 2019 from https://www.dictionary.com/browse/gracefully

[9] Sarah Diefenbach, Eva Lenz, and Marc Hassenzahl. 2013. An Interaction Vocabulary. Describing the How Of Interaction. In Conference on Human Factors in Computing Systems - Proceedings, 607-612. https://doi.org/10.1145/2468356.2468463

[10] Elisabeth Kersten van Dijk, Joyce Westerink, and Wijnand IJsselsteijn. 2016. Deceptive Visualizations and User Bias: a Case for Personalization and Ambiguity in PI Visualizations. In The 2016 ACM International foint Conference on Pervasive and Ubiquitous Computing: Adjunct, 588-593. https://doi.org/10.1145/2968219.2968326

[11] David A Ellis and Lukasz Piwek. 2018. Failing to encourage physical activity with wearable technology: what next? Journal of the Royal Society of Medicine 111, 9: 310-313. https://doi.org/10.1177/0141076818788856

[12] William W Gaver. 2003. Ambiguity as a Resource for Design. In CHI '03 Proceedings of the SIGCHI Conference on Human Factors in Computing Systems, 233-240.

[13] Peter M Gollwitzer, Kentaro Fujita, and Gabriele Oettingen. 2004. Planning and the implementation of goals. Handbook of self-regulation: Research, theory, and applications: $211-228$.

[14] Juho Hamari, Lobna Hassan, and Antonio Dias. 2018. Gamification, quantifiedself or social networking? Matching users' goals with motivational technology. User Modeling and User-Adapted Interaction 28, 1: 35-74. https://doi.org/10.1007/s11257-018-9200-2

[15] Wan Norizan Wan Hashim, Nor Laila Md Noor, and Wan Adilah Wan Adnan. 2009. The Design of Aesthetic Interaction: Towards a Graceful Interaction Framework. In Proceedings of the 2nd International Conference on Interaction Sciences: Information Technology, Culture and Human, 69-75. https://doi.org/10.1145/1655925.1655938

[16] Marc Hassenzahl, Stephanie Heidecker, Kai Eckoldt, Sarah Diefenbach, and Uwe Hillmann. 2012. All You Need is Love: Current Strategies of Mediating Intimate Relationships through Technology. ACM Transactions on ComputerHuman Interaction (TOCHI)19, 4. https://doi.org/10.1016/S0262-4079(17)323588

[17] David V.B. James, Lynne H. Johnston, Diane Crone, Adrienne H. Sidford, Chris Gidlow, Clare Morris, and Charlie Foster. 2009. Factors associated with physical activity referral uptake and participation. Fournal of Sports Sciences 27, 10: 1007-1017. https://doi.org/10.1080/02640410701468863

[18] Mark Janssen, Jeroen Scheerder, Erik Thibaut, Aarnout Brombacher, and Steven Vos. 2017. Who uses running apps and sports watches? Determinants and consumer profiles of event runners' usage of running-related smartphone applications and sports watches. PLoS ONE 12, 7: 1-17. https://doi.org/10.1371/journal.pone.0181167

[19] Mads Møller Jensen and Florian Floyd Mueller. 2014. Running with technology: Where are we heading? In Proceedings of the 26th Australian Computer-Human Interaction Conference on Designing Futures: the Future of Design, 527-530.

[20] Kristina Knaving, Paweł Wołniak, Morten Fjeld, and Staffan Björk. 2015. Flow is Not Enough: Understanding the Needs of Advanced Amateur Runners to Design Motivation Technology. In CHI '15 Proceedings of the 33rd Annual ACM
Conference on Human Factors in Computing Systems, 2013-2022. https://doi.org/10.1145/2702123.2702542

[21] Dan Lockton, Delanie Ricketts, Shruti Aditya Chowdhury, and Chang Hee Lee. 2017. Exploring Qualitative Displays and Interfaces. In Proceedings of the 2017 CHI Conference Extended Abstracts on Human Factors in Computing Systems, 1844-1852. https://doi.org/10.1145/3027063.3053165

[22] Jean-Bernard Martens. 2019. Interpreting the Diversity in Subjective Judgments. In Proceedings of the 2019 CHI Conference Extended Abstracts on Human Factors in Computing Systems. https://doi.org/10.1145/3290605.3300449

[23] Daphne Menheere, Carl Megens, Erik van der Spek, and Steven Vos. 2018. Encouraging physical activity and self-enhancement in women with breast cancer through a smart bra. In In Proceedings of DRS: Design Research Society 2018: Design Research Society. https://doi.org/10.21606/dma.2018.437

[24] Daphne Menheere. 2015. Activogue: A fashion forward activity tracker. Master's report. Eindhoven University of Technology department of Industrial Design, Eindhoven, the Netherlands.

[25] Florian Mueller, Frank Vetere, Martin R. Gibbs, Darren Edge, Stefan Agamanolis, and Jennifer G. Sheridan. 2010. Jogging over a distance between Europe and Australia. In Proceedings of the 23nd annual ACM symposium on User interface software and technology - UIST '10, 189. https://doi.org/10.1145/1866029.1866062

[26] Peeters, M. M. R., \& Megens, C. J. P. G. (2014). Experiential design landscapes: how to design for behaviour change, towards an active lifestyle.

[27] Lisa Pridgeon and Sarah Grogan. 2012. Understanding exercise adherence and dropout: An interpretative phenomenological analysis of men and women's accounts of gym attendance and non-attendance. Qualitative Research in Sport, Exercise Health 4, and 3: 382-399. https://doi.org/10.1080/2159676X.2012.712984

[28] Ryan E. Rhodes and Gert Jan De Bruijn. 2013. How big is the physical activity intention-behaviour gap? A meta-analysis using the action control framework. British Journal of Health Psychology 18, 2: 296-309. https://doi.org/10.1111/bjhp.12032

[29] Amy A. Ross. 2018. Tracking Health and Fitness: A Cultural Examination of Self-quantification, Biomedicalization, and Gender. eHealth: Current Evidence, Promises, Perils and Future Directions Studies in Media and Communications 15: 123-151. https://doi.org/10.1108/s2050-206020180000015003

[30] Richard M. Ryan, Christina M. Frederick, Deborah Lepes, Noel Rubio, and Kennon M. Sheldon. 1997. Intrinsic Motivation and Exercise Adherence. International fournal of Sport Psychology 28: 335-354.

[31] Tanya Maria Filomena Scarapicchia, Steve Amireault, Guy Faulkner, and Catherine Michelle Sabiston. 2017. Social support and physical activity participation among healthy adults: A systematic review of prospective studies. International Review of Sport and Exercise Psychology 10, 1: 50-83. https://doi.org/10.1080/1750984X.2016.1183222

[32] Jeroen Scheerder, Koen Breedveld, \& Julie Borgers. 2015. Running across Europe: the rise and size of one of the largest sport markets. Springer.

[33] Patrick C Shih and The Pennsylvania. 2015. Use and Adoption Challenges of Wearable Activity Trackers. In IConference 2015 Proceedings.

[34] Smart Wearable Fitness and Sports Devices Market 2019: Global Key Players, Trends, Share, Industry Size, Segmentation, Opportunities, Forecast To 2025 Retrieved June 25, 2019 from https://www.reuters.com/brandfeatures/venturecapital/article?id=120311

[35] Jeroen Stragier, Peter Mechant, Lieven De Marez, and Greet Cardon. 2018. Computer-Mediated Social Support for Physical Activity: A Content Analysis. Health Education and Behavior 45, 1: 124-131. https://doi.org/10.1177/1090198117703055

[36] Jeroen Stragier, Mariek Vanden Abeele, and Lieven De Marez. 2018 Recreational athletes ' running motivations as predictors of their use of online fitness community features. Behaviour \& Information Technology 37, 8: 815827. https://doi.org/10.1080/0144929X.2018.1484516

[37] Stewart G Trost, Steven N Blair, and Karin M Khan. 2014. Physical inactivity remains the greatest public health problem of the 21st century: evidence, improved methods and solutions using the " 7 investments that work" as a framework. British fournal of Sports Medicine 48, 5: 394-401. https://doi.org/10.1136/bjsports-2013-092492

[38] Maarten Versteeg, Elise van den Hoven, and Caroline Hummels. 2016. Interactive Jewellery: A Design Exploration. In Proceedings of the TEI '16: Tenth International Conference on Tangible, Embedded, and Embodied Interaction, 44-52. https://doi.org/10.1145/2839462.2839504

[39] Steven Vos, Ruben Walravens, Paul Hover, Julie Borgers, and Jeroen Scheerder. 2014. For Fun or Prestige? Typology of event runners [Voor de pret of de prestatie? Typologieen van evenementenloopsters.] Vrijetijdsstudies 32, 2: $19-34$.

[40] Steven Vos, Mark Janssen, Jos Goudsmit, Coen Lauwerijssen, and Aarnout Brombacher. 2016. From Problem to Solution: Developing a Personalized Smartphone Application for Recreational Runners following a Three-step Design Approach. Procedia Engineering 147, December: 799-805. https://doi.org/10.1016/j.proeng.2016.06.311 
[41] Steven Vos. 2016. Designerly solutions for vital people. Eindhoven: Eindhoven University of Technology

[42] Jayne Wallace, James Thomas, Derek Anderson, and Patrick Olivier. 2013 Mortality as Framed by Ongoingness in Digital Design. Design Issues 29, 4: 15. https://doi.org/10.1162/DESI
[43] Paweł Woźniak, Kristina Knaving, Staffan Björk, and Morten Fjeld. 2015. RUFUS: Remote Supporter Feedback for Long-Distance Runners. In Proceedings of the 17th International Conference on Human-Computer Interaction with Mobile Devices and Services, 115-124. https://doi.org/10.1145/2785830.2785893 